\title{
Study on Conformation Interconversion of 3-Alkyl-4-acetyl-3,4-dihydro-2H-1,4-benzoxazines from Dynamic NMR Experiments and ab Initio Density Functional Calculations
}

\author{
Gang Yang, Xiuwen Han, Weiping Zhang, Xiumei Liu, Pengyu Yang, Yonggui Zhou, and \\ Xinhe Bao* \\ State Key Laboratory of Catalysis, Dalian Institute of Chemical Physics, Chinese Academy of Sciences, \\ Dalian 116023, People's Republic of China
}

Received: February 20, 2005; In Final Form: July 25, 2005

\begin{abstract}
Variable-temperature NMR experiments and ab initio density functional calculations were carried out to investigate the conformation interconversion of novel chiral 3-alkyl-3,4-dihydro- $2 H$-benzo[1,4]oxazine derivatives. With $\mathrm{CDCl}_{3}$ as the solvent, the coalescence temperatures of $\mathrm{H}_{2}, \mathrm{H}_{3}, \mathrm{H}_{11}$, and $\mathrm{H}_{19}$ of product $\mathbf{1}$ are about 289, 304, 292, and $316 \mathrm{~K}$, with the corresponding activation free energies at $58.0 \pm 6.7,60.9 \pm 7.1$, $58.3 \pm 6.8$, and $59.6 \pm 6.9 \mathrm{~kJ} \cdot \mathrm{mol}^{-1}$, respectively. When dimethyl sulfoxide (DMSO- $d_{6}$ ) was used as the solvent, ${ }^{1} \mathrm{H}$ and ${ }^{13} \mathrm{C}$ NMR signals were completely assigned at $375 \mathrm{~K}$. The effects of solvent and temperature were investigated through a polarizable continuum model. At each theoretical level (MP2 or B3LYP), the changing tendencies of the calculated activation free energies and interconversion rates agree well with those of the NMR results. In addition, the interconversion rate at each specified temperature was calculated to be about 1.5 times faster in DMSO- $d_{6}$ than in $\mathrm{CDCl}_{3}$. Accordingly, we failed to observe the coalescence phenomena of $\mathrm{H}_{3}$ and $\mathrm{H}_{19}$ in DMSO- $d_{6}$ by NMR measurements from 296 to $375 \mathrm{~K}$. The substitution effect at the $\mathrm{R}_{1}-\mathrm{R}_{5}$ positions was considered using density functional calculations, with the activation barriers decreasing as follows: product $\mathbf{6}>\mathbf{3}>\mathbf{1}>\mathbf{7}>\mathbf{2}$. This sequence is consistent with that of the reaction heats, except for product 7, implying that the interconversion processes may be thermodynamically controlled. Surprisingly, the substituted groups near the acetyl group in product 2 and 7 do not elevate the activation barrier but, instead, lower it somewhat, with the possible reasons for this provided in the paper.
\end{abstract}

\section{Introduction}

The strong drive to obtain highly active drugs has exploited numerous novel 3- substituted-4-acetyl-3,4-dihydro- $2 H$-1,4-benzoxazine derivatives. ${ }^{1-4}$ Following the conventional and economical synthesis route reported by Kundu et al., ${ }^{5}$ we have successfully obtained a number of novel optically active 3-alkyl-3,4dihydro- $2 H$-benzo[1,4]oxazine derivatives, as presented in Scheme $1 .^{6}$

The dynamic NMR technique has been well-acknowledged as being powerful enough to investigate the conformation interconversions, acquiring information such as coalescence temperatures, activation free energies, and exchange rates. ${ }^{7-13}$ Aided with density functional calculations, Akhmedov et al. ${ }^{12}$ confirmed that the two rotamers of methyl-8-(2-furyl)-5-methyl1,3-dioxo-3,3a,4,6,8,9,9a,9b-octahydrofuro[3,4-f]isoquinoline$7(1 \mathrm{H})$ carboxylate are formed by the different orientations of the $\mathrm{C}-\mathrm{N}$ bond. Combined with quantum NMR calculations, Jorge et al. ${ }^{13}$ resolved the complete conformational properties of sulfonium salt glycosidase inhibitors in solution. Gradually, theoretical calculations were also accepted as possessing great potential in studying conformation interconversions. With semiempirical theoretical methods (AMPAC and INDO/S), Belletete et al. ${ }^{14}$ obtained the activation barrier of the conformation interconversion and the absolute minimum for 2,2'-bithiophene by comparing its configurations in the gas phase and in solution. Using the density functional method, Jose et al. ${ }^{15}$ calculated the $\alpha-\beta$ anomer energy difference of counterclockwise Dglucopyranose, and the stability of the different rotamers was compared in either a vacuum or an aqueous solution.

\footnotetext{
* To whom correspondence should be addressed. E-mail: xhbao@ dicp.ac.cn.
}

However, only very few attempts have been made to resolve the mechanism of conformation interconversions to date. ${ }^{12,14}$ Moreover, in our system, four $\mathrm{H}$ atoms are involved during the conformation interconversion. Therefore, it is not trivial to assign the ${ }^{1} \mathrm{H}$ or ${ }^{13} \mathrm{C}$ NMR signals individually, let alone understand clearly the process of conformation interconversions. First, in this study, variable-temperature NMR experiments were performed in two solvents, chloroform $\left(\mathrm{CDCl}_{3}\right)$ and dimethyl sulfoxide (DMSO- $d_{6}$ ). The conformation interconversion was investigated in $\mathrm{CDCl}_{3}$, which has a lower freezing point, with the activation free energies and interconversion rates obtained at each temperature. The assignments of ${ }^{1} \mathrm{H}$ and ${ }^{13} \mathrm{C}$ NMR spectra were completed in DMSO- $d_{6}$, which has a higher boiling point. Second, the effectiveness of basis sets was checked as intramolecular hydrogen bonding played an important role in our system. Third, the effects of solvent and temperature were studied through the polarizable continuum model (PCM) approach. Finally, the transition state (TS) structures were located for the two conformations of the above products, studying the substitution effect at the $\mathrm{R}_{1}-\mathrm{R}_{5}$ positions. Comparisons between the experimental and the calculated results were made throughout the paper.

\section{Experimental Details}

A number of optically active 3-substituted-4-acetyl-3,4dihydro- $2 H-1,4$ - benzoxazines were synthesized according to the previous procedure. ${ }^{6}$ The samples were dissolved in organic solvent; either $\mathrm{CDCl}_{3}$ or DMSO- $d_{6}$ was used for the NMR measurements. All the NMR spectra were recorded on a Bruker DRX-400 NMR spectrometer $\left(400 \mathrm{MHz}\right.$ for ${ }^{1} \mathrm{H}$ and $100 \mathrm{MHz}$ for ${ }^{13} \mathrm{C}$ ) equipped with a $5-\mathrm{mm}$ indirect detection probe with a 
SCHEME 1: Hydrogenation of 3-Arylidene-3,4-dihydro-2H-1,4-benzoxazines to the Desired Products of 3-Alkyl-3,4-dihydro-2H-1,4-benzoxazines ${ }^{a}$

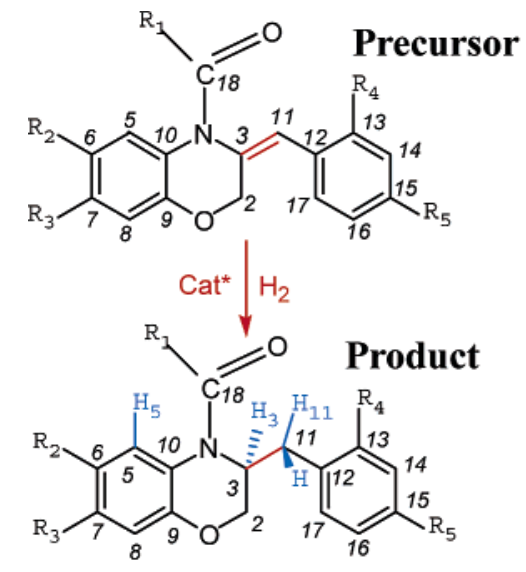

(1): $R_{1}=M e, R_{2}=R_{3}=R_{4}=R_{5}=H$

(2): $R_{1}=B z, R_{2}=R_{3}=R_{4}=R_{5}=H$

(3): $R_{1}=M e, R_{2}=M e, R_{3}=R_{4}=R_{5}=H$

(4): $\mathrm{R}_{1}=M e, \mathrm{R}_{2}=\mathrm{OMe}, \mathrm{R}_{3}=\mathrm{R}_{4}=\mathrm{R}_{5}=\mathrm{H}$

(5): $\mathrm{R}_{1}=\mathrm{Me}, \mathrm{R}_{2}=\mathrm{Cl}, \mathrm{R}_{3}=\mathrm{R}_{4}=\mathrm{R}_{5}=\mathrm{H}$

(6): $R_{1}=M e, R_{2}=R_{3}=R_{5}=H, R_{4}=M e$

(7): $R_{1}=M e, R_{2}=R_{3}=R_{5}=H, R_{4}=O M e$

(8): $R_{1}=M e, R_{2}=H, R_{3}=M e, R_{4}=R_{5}=H$

(9): $R_{1}=M e, R_{2}=R_{3}=R_{4}=H, R_{5}=M e$

(10): $R_{1}=M e, R_{2}=R_{3}=R_{4}=H, R_{5}=O M e$

(11): $R_{1}=R A$ (see below), $R_{2}=R_{3}=R_{4}=R_{5}=H$

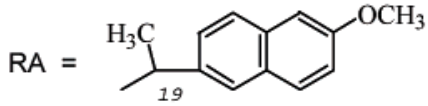

Variety of substituted groups at $R_{1} \sim R_{5}$ positions

${ }^{a} \mathrm{C}=\mathrm{C}$ double bond to be hydrogenated is in red; $\mathrm{H}$ atoms possibly involved in hydrogen bonds are in blue.

$Z$ gradient. In $\mathrm{CDCl}_{3}$, which has a lower freezing point, the process of conformation interconversions was carefully analyzed, where the interconversion rate was rather slow on the NMR time scale; in DMSO- $d_{6}$, which has a higher boiling point, the complete assignments of ${ }^{1} \mathrm{H}$ and ${ }^{13} \mathrm{C}$ NMR spectra were carried out, where the interconversion rate was fast on the NMR time scale. Besides the one-dimensional NMR technique, a lot of two-dimensional (2D) NMR techniques were applied to assign the NMR spectra, including ${ }^{1} \mathrm{H}-{ }^{1} \mathrm{H}$ correlation spectroscopy (COSY), total correlation spectroscopy (TOCSY), and proton-detecting heteronuclear 2D techniques [heteronuclear multiple-quantum coherence (HMQC), heteronuclear multiplebond correlation (HMBC)].

\section{Computational Details}

All the theoretical calculations reported here were performed using Gaussian 98 software. ${ }^{16}$ Albeit molecular mechanics or semiempirical methods have been reported, producing satisfactory results; $7,11,14$ however, they may fail to treat complex systems such as ours or to obtain the correct TS structures. Highlevel $a b$ initio methods were qualified but too timeconsuming; ${ }^{12-13,15}$ therefore, the economical and yet reliable density functional B3LYP was employed in this study ${ }^{17,18}$ along with the standard split-valence $6-31 \mathrm{G}^{*}$ basis set. ${ }^{19}$ Because the weak interaction of intramolecular hydrogen bonding plays an important role in our system, some conformations were also optimized with the very time-consuming $6-311++\mathrm{G}^{* *}$ basis set to check the validity of the $6-31 G^{*}$ basis set. The conformations of product $\mathbf{1}$ were verified at the stationary points by analyzing the Hessian matrices of the energy second derivatives. Zero-point energy (ZPE) corrections were made with the $6-31 \mathrm{G}^{*}$ basis set.

Solvent continuum effects were calculated for product $\mathbf{1}$ using the gas-phase optimized geometries in conjunction with the PCM (real cavity PCM). ${ }^{20,21}$ Thermochemistry calculations were performed at the experimental pressure and temperatures (1 atm, 229-316 K), accounting for entropy effects associated with the ligand coordination. Whether in the gas phase or in solution, the rate constant and thermodynamic properties were correlated through the Eyring equation within the TS theory:22

$$
\begin{aligned}
& k_{i}=k_{\mathrm{B}} T / h \exp \left(-\Delta G_{i} / R T\right)= \\
& k_{\mathrm{B}} T / h \exp \left(-\Delta S_{i} / R\right) \exp \left(-\Delta H_{i} / R T\right)
\end{aligned}
$$

where $h, k_{\mathrm{B}}$, and $R$ represent the Planck constant, the Boltzmann constant, and the gas constant, respectively. $\Delta G_{i}, \Delta S_{i}$, and $\Delta H_{i}$ refer to the activation free energy, the entropic activation barrier, and the enthalpic activation barrier, respectively. When the entropy effect is incorporated, the activation free energy provides a more complete representation of intrinsic reaction kinetics at nonzero temperatures than the electronic activation barrier.

\section{Results and Discussion}

Each product in Scheme 1 possessed altogether four possible conformations owing to the presence of the $\mathrm{C}_{3}$ chiral center and the difference in acetyl orientation (see Figure 1 with product $\mathbf{1}$ as the example). Conformations $\mathbf{1 a}, \mathbf{b}$ belong to the $S$ configuration, whereas conformations $\mathbf{1 c}, \mathbf{d}$ belong to the $R$ configuration. However, here we just focus the study on conformations 1a,b because of the following three reasons: (1) One absolute configuration is predominant in the synthesized products (ca. 98\% ee). ${ }^{6}$ (2) The interconversion between conformation 1c and conformation 1d is totally the same as that between conformation $\mathbf{1 a}$ and conformation $\mathbf{1 b}$, that is, by rotating the acetyl group by approximately $180^{\circ}$. (3) The NMR signals of conformations 1a,c are exactly the same, and those of conformations $\mathbf{1 b}, \mathbf{d}$ are also exactly the same. Therefore, this has led to the investigation of the interconversion either between conformation 1a and conformation $\mathbf{1 b}$ or between conformation 1c and conformation $\mathbf{1 d}$.

4.1. Features of ${ }^{1} \mathbf{H}$ and ${ }^{13} \mathrm{C}$ NMR Spectra. During the exploration of asymmetric hydrogenation it was found that the features of the ${ }^{1} \mathrm{H}$ and ${ }^{13} \mathrm{C}$ NMR spectra of the products at ambient temperature were seriously broadened. When $C_{3}$ is a carbon of a double bond before hydrogenation (see the precursors in Scheme 1), the NMR signals are very narrow and can be assigned individually. The spectral lines are still distinguishable after asymmetric hydrogenation if the $\mathrm{N}$ atom in the oxazine ring is connected to a $\mathrm{H}$ or a symmetric functional group such as Ts.

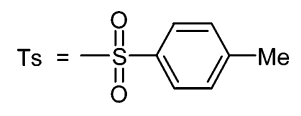

However, when the $\mathrm{N}$ atom in the oxazine ring is connected to the acetyl group, the NMR signals are seriously broadened and hard to analyze at ambient temperature. It is clear that the roomtemperature spectra were recorded in the slow exchange region. 


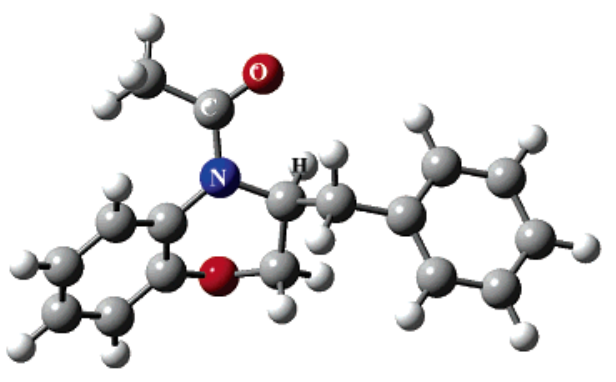

(A) Product(1a)

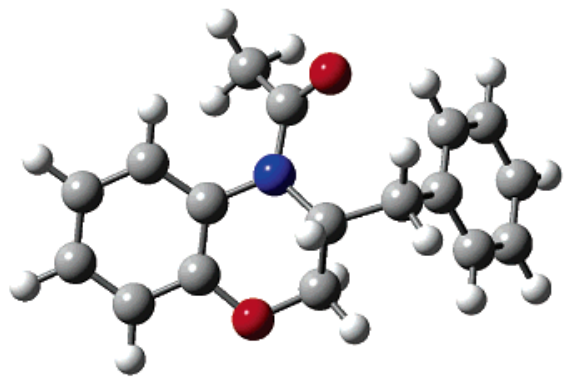

(C) Product(1c)

(E) Product(t1)

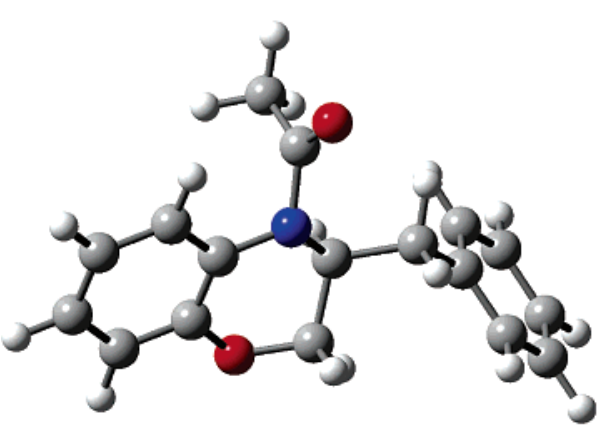

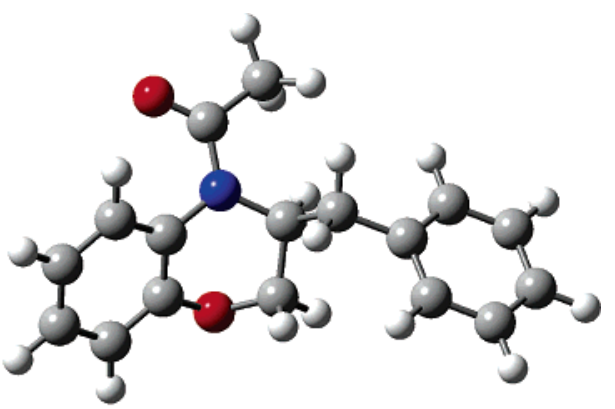

(B) Product(1b)

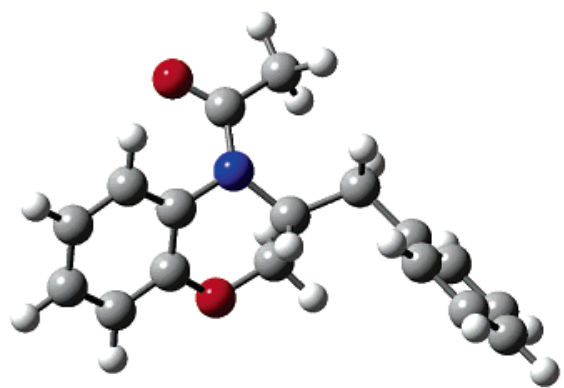

(D) Product(1d)

Figure 1. Four possible conformations of product $\mathbf{1}$ and the TS structure $\mathbf{t} \mathbf{1}$ between conformation $\mathbf{1 a}$ and conformation $\mathbf{1 b}$.

Figures S1 and S2 (see Supporting Information) display the changes of the ${ }^{1} \mathrm{H}$ and ${ }^{13} \mathrm{C}$ spectra of product 1 in DMSO- $d_{6}$ at $296,315,336,356$, and $375 \mathrm{~K}$, respectively. The spectral lines became narrow as the temperature increased. The high-resolution ${ }^{1} \mathrm{H}$ and ${ }^{13} \mathrm{C}$ NMR spectra were obtained at $375 \mathrm{~K}$ with the $\mathrm{C}_{3}$ signal appearing at $50.9 \mathrm{ppm}$. Compared with the ${ }^{1} \mathrm{H}$ chemical shifts of products $\mathbf{1 - 1 0}, \mathrm{H}_{3}$ goes upfield by around $1.2 \mathrm{ppm}$ while the two $\mathrm{H}_{2}$ protons go upfield by $0.3-0.4 \mathrm{ppm}$ if the $\mathrm{N}$ atom is connected to the $\mathrm{H}$. If the $\mathrm{N}$ atom is connected to the Ts group, $\mathrm{H}_{3}$ is slightly changed, whereas the two $\mathrm{H}_{2}$ protons go upfield by 0.2 and $0.9 \mathrm{ppm}$, respectively. Aided by 2D NMR techniques such as ${ }^{1} \mathrm{H}-{ }^{1} \mathrm{H}$ COSY, TOCSY, HMQC, and $\mathrm{HMBC}$, the assignments of the ${ }^{1} \mathrm{H}$ and ${ }^{13} \mathrm{C}$ NMR spectra were completed and collected in Tables S1 and S2 (see Supporting Information), respectively.

The ${ }^{1} \mathrm{H}$ and ${ }^{13} \mathrm{C}$ NMR spectra of product 1 dissolved in $\mathrm{CDCl}_{3}$ $(229-328 \mathrm{~K})$ are displayed in Figures 2 and 3. Through the analysis of ${ }^{1} \mathrm{H}$ NMR spectra, the coalescence temperatures of $\mathrm{H}_{2}, \mathrm{H}_{3}, \mathrm{H}_{11}$, and $\mathrm{H}_{19}$ were obtained at about 289, 316, 292, and $304 \mathrm{~K}$, respectively. For each of the four $\mathrm{H}$ atoms, the conformation interconversion is very slow below the coalescence temperature and different conformations can be distinguished from the NMR spectra. When increasing the temperature above the coalescence temperature, the NMR signals become narrower and the intensities are strengthened, which is analogous to the phenomena in DMSO- $d_{6}$. A ${ }^{1} \mathrm{H}$ NMR spectrum at room temperature (292 K) was enlarged and is shown in Figure S3 (see Supporting Information), from where the population ratio of conformations $\mathbf{1 a} / \mathbf{1 b}$ was obtained as about 2.0 after integrating the ${ }^{1} \mathrm{H}$ NMR spectra.

4.2. Kinetic Studies Based on Variable-Temperature NMR Experiments. At different temperatures, the rates of conformation interconversion $\left(k_{\mathrm{e}}\right)$ can be defined as follows: ${ }^{23}$

$$
k_{\mathrm{e}}= \begin{cases}\frac{\pi \Delta v_{\mathrm{a}}}{v_{\mathrm{a}}-v_{\mathrm{b}}} & \left(T<T_{\mathrm{C}}\right) \\ \frac{4 \pi p_{\mathrm{a}} p_{\mathrm{b}}{ }^{2}\left(v_{\mathrm{a}}-v_{\mathrm{b}}\right)^{2}}{\Delta v_{\mathrm{ab}}} & \left(T>T_{\mathrm{C}}\right)\end{cases}
$$

where $T_{\mathrm{c}}$ is the coalescence temperature. $\Delta v_{\mathrm{a}}$ represents the peak width of conformation $1 \mathrm{a}$ (in $\mathrm{Hz}$ ). $v_{\mathrm{a}}-v_{\mathrm{b}}$ refers to the difference in the chemical shifts of the same $\mathrm{H}$ between conformation $\mathbf{1 a}$ and conformation $\mathbf{1 b}$, which remains almost constant for $\mathrm{H}_{2}, \mathrm{H}_{3}, \mathrm{H}_{11}$, and $\mathrm{H}_{19}$ within the temperature range of $233-263 \mathrm{~K}$ and at $70.4,9.2,61.6$, and $195.5 \mathrm{~Hz}$, respectively. As the temperature continues to increase, these values quickly approach zero. $p_{\mathrm{a}}$ and $p_{\mathrm{b}}$ are the relative populations of conformations $\mathbf{1 a}, \mathbf{b}$. When $p_{\mathrm{a}} / p_{\mathrm{b}}$ is 2.0 , the constant $\Omega$ equals 0.662 . 


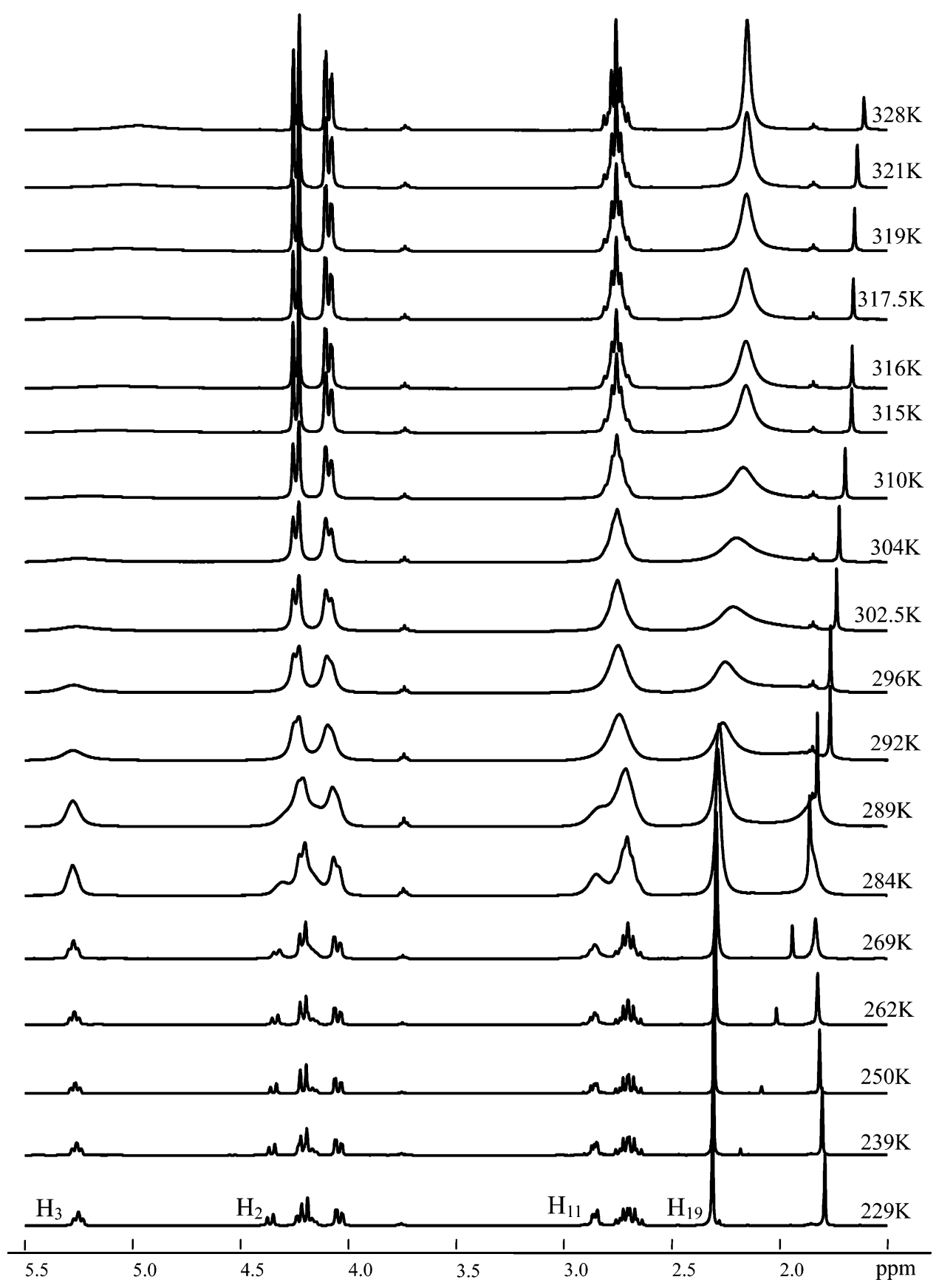

Figure 2. Variable-temperature ${ }^{1} \mathrm{H}$ NMR spectra of product $\mathbf{1}$ in $\mathrm{CDCl}_{3}$ (high field).

When eq 2 is used, the interconversion rates for $\mathrm{H}_{2}, \mathrm{H}_{3}, \mathrm{H}_{11}$, and $\mathrm{H}_{19}$ at various temperatures were obtained and collected in Table 1 . Normally, the interconversion rate $\left(k_{\mathrm{e}}\right)$ of each $\mathrm{H}$ should increase as the temperature increases. However, there are some exceptions. For instance, $k_{\mathrm{e}}$ for $\mathrm{H}_{2}$ at $239 \mathrm{~K}$ is slightly smaller than at $229 \mathrm{~K}$, which is caused by the experimental errors in determining $\Delta v_{\mathrm{a}}$ values. Through the plot of $-R \ln \left(h k_{\mathrm{e}} / k_{\mathrm{B}} T\right)$ versus $1 / T$ (Figure 4), the enthalpic and entropic activation barriers $\left(\Delta H_{\mathrm{e}}\right.$ and $\left.\Delta S_{\mathrm{e}}\right)$ and, subsequently, the activation free energies for $\mathrm{H}_{2}, \mathrm{H}_{3}, \mathrm{H}_{11}$, and $\mathrm{H}_{19}$ were obtained, respectively. For each $\mathrm{H}$, the activation free energies may not increase monotonically with the temperature. However, when the four activation free energies at each temperature were averaged, the average (labeled as $\Delta G_{\mathrm{e}}$, see Table 1) has a monotonic tendency to change with the temperature, which may be caused by the counteracted errors of these four $\mathrm{H}$ atoms. It should be noted that the largest possible experimental errors of the $\Delta G_{\mathrm{e}}$ values are shown in Table 1.
For methylene, there exists an alternative way to calculate the activated free energy at the coalescence temperature $\left(\Delta G_{\mathrm{c}}\right):^{24}$

$$
\begin{aligned}
\Delta G_{\mathrm{c}}\left(\mathrm{kJ} \cdot \mathrm{mol}^{-1}\right)=1.912 \times 10^{-2} T_{\mathrm{c}}\{9.97+ \\
\left.\log \left[T_{\mathrm{c}} /\left(\delta v^{2}+6 J^{2}\right)^{1 / 2}\right]\right\}
\end{aligned}
$$

Correspondingly, the interconversion rate was formalized as

$$
k_{\mathrm{c}}=\pi\left(\delta v^{2}+6 J^{2}\right)^{1 / 2} / 2^{1 / 2}
$$

where $\delta v$ is the difference of the chemical shifts between the centers of the two doublets, equal to 60.9 and $21.1 \mathrm{~Hz}$ for $\mathrm{H}_{2}$ and $\mathrm{H}_{11}$, respectively. The coupling constant of the geminal protons is defined as $J$ and is equal to 11.0 and $13.8 \mathrm{~Hz}$ for $\mathrm{H}_{2}$ and $\mathrm{H}_{11}$, respectively. At the coalescence temperature, $\Delta G_{\mathrm{c}}$ was calculated using eq 3 and found to be 58.6 and $60.5 \mathrm{~kJ} \cdot \mathrm{mol}^{-1}$ 


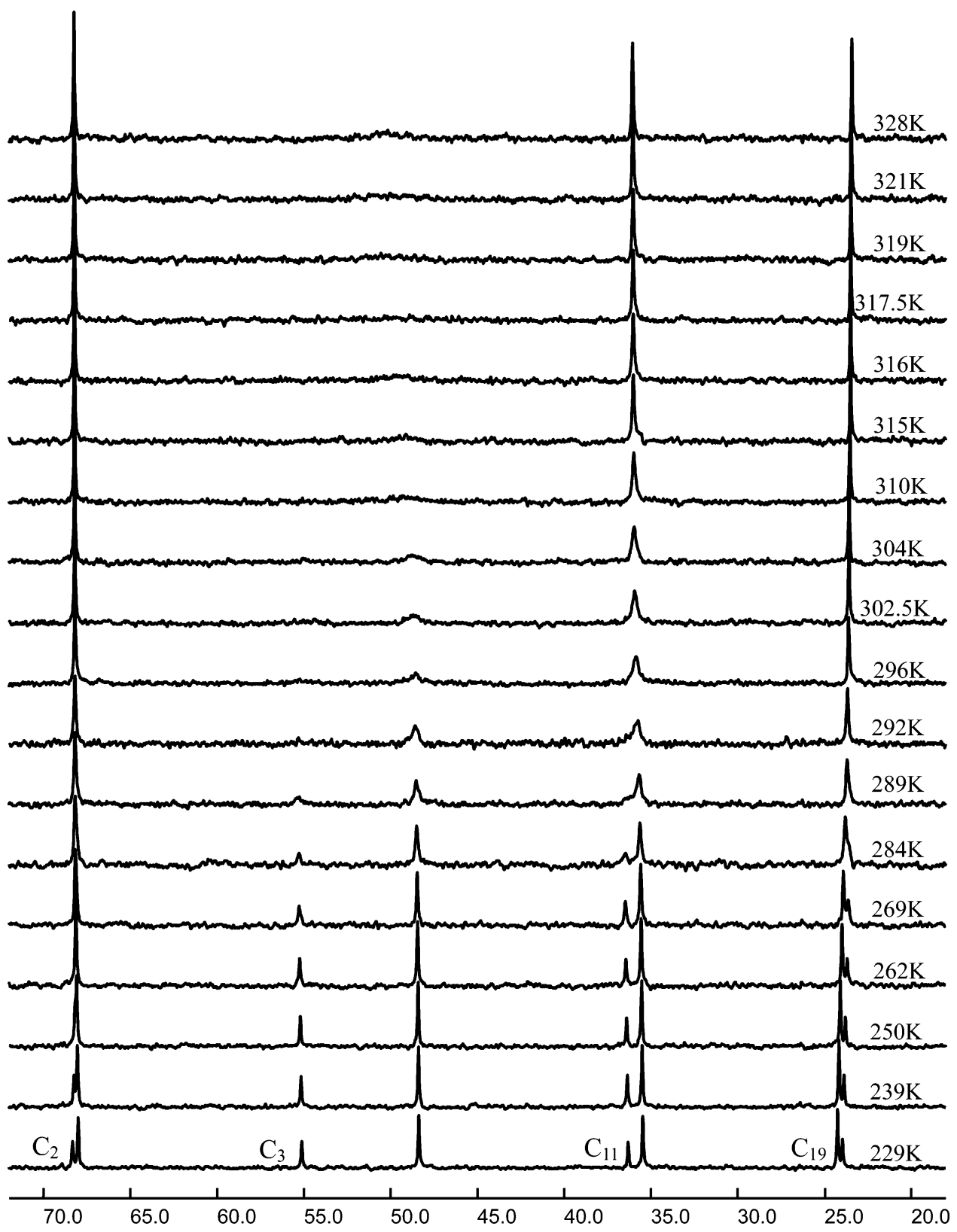

Figure 3. Variable-temperature ${ }^{13} \mathrm{C} \mathrm{NMR}$ spectra of product $\mathbf{1}$ in $\mathrm{CDCl}_{3}$ (high field).

for $\mathrm{H}_{2}$ and $\mathrm{H}_{11}$, respectively, agreeing well with the corresponding values originating from eq $2(57.6 \pm 3.2$ and $59.1 \pm 3.4$ $\left.\mathrm{kJ} \cdot \mathrm{mol}^{-1}\right)$. The excellent agreement of the activation free energies from these two methods further confirmed the reliability of the NMR technique in studying the kinetic processes of conformation interconversions.

In $\mathrm{CDCl}_{3}$, the coalescence temperatures for $\mathrm{H}_{3}$ and $\mathrm{H}_{19}$ are 316 and $304 \mathrm{~K}$. Accordingly, we should have observed the coalescence phenomena in DMSO- $d_{6}$ through the variabletemperature NMR experiments from 296 to 375 K. However, no such trace was captured from either ${ }^{1} \mathrm{H}$ or ${ }^{13} \mathrm{C}$ NMR spectra (see Figures $\mathrm{S} 1$ or $\mathrm{S} 2$ of Supporting Information). This may be a result of the faster interconversion rate in DMSO- $d_{6}$ than in $\mathrm{CDCl}_{3}$. As a result, the coalescence temperature for the same $\mathrm{H}$ is lower in DMSO- $d_{6}$ than in $\mathrm{CDCl}_{3}$.

4.3. Effect of Basis Sets on Geometries and Energy Differences. As the weak interaction of intramolecular hydrogen bonding is involved in the conformation interconversion, two different basis sets, $6-31 \mathrm{G}^{*}$ and $6-311++\mathrm{G}^{* *}$, were used to evaluate their validity. The energy difference between confor- mation $1 \mathbf{a}$ and conformation $\mathbf{1 b}$ is $16.90 \mathrm{~kJ} \cdot \mathrm{mol}^{-1}$ with the $6-31 \mathrm{G}^{*}$ basis set and $16.45 \mathrm{~kJ} \cdot \mathrm{mol}^{-1}$ with the $6-311++\mathrm{G}^{* *}$ basis set, respectively, which determines that basis sets have no substantial influence on the energy difference. Under the 6-31G* basis set, these two conformations were verified at the stationary points by analyzing the Hessian matrices of the energy derivatives. With ZPE corrections included, the energy difference is $16.00 \mathrm{~kJ} \cdot \mathrm{mol}^{-1}$. Such a small value means that neither of the two conformations plays a predominant role and that the interconversion rate will proceed fast at ambient temperature, causing the NMR peaks to become too broad to assign individually.

For all the products, direct bonds such as $\mathrm{C}_{18}-\mathrm{N}$ and $\mathrm{C}=\mathrm{O}$ are much less affected by the basis sets than hydrogen bonds $\left(\mathrm{O}-\mathrm{H}_{3}, \mathrm{O}-\mathrm{H}_{11}\right.$, and $\left.\mathrm{O}-\mathrm{H}_{5}\right)$. Even for the hydrogen bonds, the changes in their distances were within the order of $10^{-2} \AA$. For the more stable conformations, such as $\mathbf{1 a}, \mathbf{2 a}, \mathbf{3 a}, \mathbf{6 a}$, and $\mathbf{7 a}$, the differences made by the two basis sets in the $\mathrm{C}_{3} \mathrm{NC}_{18} \mathrm{O}$ dihedral are less than $1^{\circ}$. As to conformation $\mathbf{1 b}$, the difference in the $\mathrm{C}_{3} \mathrm{NC}_{18} \mathrm{O}$ dihedral made by the two basis sets is less than 
TABLE 1: Conformation Interconversion Rates $\left[k_{i}\left(s^{-1}\right)\right]$ for Product 1 at Different Temperatures as Well as the Corresponding Activation Free Energies $\left[\Delta G_{i}\left(\mathbf{k J} \cdot \mathbf{m o l}^{-1}\right)\right]$

\begin{tabular}{|c|c|c|c|c|c|c|c|c|c|c|}
\hline \multirow[b]{2}{*}{$T(\mathrm{~K})$} & & \multicolumn{3}{|c|}{ calculated from the NMR experiments } & \multicolumn{6}{|c|}{ calculated from the PCM } \\
\hline & & $\Delta v_{\mathrm{ab}}$ & $k_{\mathrm{e}}$ & $\Delta G_{\mathrm{e}}$ & $k_{\mathrm{b}}$ & $\Delta G_{\mathrm{b}}$ & $k_{\mathrm{m}}$ & $\Delta G_{\mathrm{m}}$ & $k_{\mathrm{d}}$ & $\Delta G_{\mathrm{d}}$ \\
\hline 229 & $\begin{array}{l}\mathrm{H}_{2} \\
\mathrm{H}_{3} \\
\mathrm{H}_{11} \\
\mathrm{H}_{19}\end{array}$ & $\begin{array}{l}8.0 \\
6.6 \\
7.0 \\
2.6\end{array}$ & $\begin{array}{r}25.1 \\
20.7 \\
22.0 \\
8.2\end{array}$ & $51.8 \pm 6.0$ & 1.5 & 54.84 & 1.8 & 54.48 & 2.7 & 53.69 \\
\hline 239 & $\begin{array}{l}\mathrm{H}_{2} \\
\mathrm{H}_{3} \\
\mathrm{H}_{11} \\
\mathrm{H}_{19}\end{array}$ & $\begin{array}{l}7.0 \\
6.2 \\
7.0 \\
2.6\end{array}$ & $\begin{array}{r}22.0 \\
19.5 \\
22.0 \\
8.2\end{array}$ & $52.8 \pm 6.2$ & & & & & & \\
\hline 250 & $\begin{array}{l}\mathrm{H}_{2} \\
\mathrm{H}_{3} \\
\mathrm{H}_{11} \\
\mathrm{H}_{19}\end{array}$ & $\begin{array}{r}11.0 \\
6.2 \\
7.0 \\
2.6\end{array}$ & $\begin{array}{r}34.6 \\
19.5 \\
22.0 \\
8.2\end{array}$ & $53.9 \pm 6.3$ & 7.8 & 54.88 & 20.6 & 54.57 & & \\
\hline 262 & $\begin{array}{l}\mathrm{H}_{2} \\
\mathrm{H}_{3} \\
\mathrm{H}_{11} \\
\mathrm{H}_{19}\end{array}$ & $\begin{array}{r}12.0 \\
7.3 \\
7.5 \\
3.0\end{array}$ & $\begin{array}{r}37.7 \\
22.9 \\
23.6 \\
9.4\end{array}$ & $55.2 \pm 6.4$ & & & & & & \\
\hline 269 & $\begin{array}{l}\mathrm{H}_{2} \\
\mathrm{H}_{3} \\
\mathrm{H}_{11} \\
\mathrm{H}_{19}\end{array}$ & $\begin{array}{r}19.0 \\
18.7 \\
10.0 \\
5.5\end{array}$ & $\begin{array}{l}59.7 \\
58.7 \\
31.4 \\
17.3\end{array}$ & $55.9 \pm 6.5$ & 120.7 & 54.93 & 136.8 & 54.65 & 210.2 & 53.69 \\
\hline 289 & $\begin{array}{l}\mathbf{H}_{2}{ }^{a} \\
\mathrm{H}_{3} \\
\mathrm{H}_{11} \\
\mathrm{H}_{19} \\
\boldsymbol{H}_{2}{ }^{b}\end{array}$ & $\begin{array}{l}\mathbf{3 4 . 3} \\
29.0 \\
20.0 \\
18.7 \\
11.0\end{array}$ & $\begin{array}{r}\mathbf{1 0 6 . 3} \\
91.1 \\
62.8 \\
58.7 \\
\mathbf{1 4 7 . 9}\end{array}$ & $\begin{array}{l}58.0 \pm 6.7 \\
57.6 \pm \mathbf{3 . 2}\end{array}$ & & & & & & \\
\hline 292 & $\begin{array}{l}\mathrm{H}_{2} \\
\mathrm{H}_{3} \\
\mathbf{H}_{11}{ }^{a} \\
\mathrm{H}_{19}{ }^{a} \\
\boldsymbol{H}_{11}{ }^{b}\end{array}$ & $\begin{array}{l}30.4 \\
33.4 \\
\mathbf{4 5 . 1} \\
26.8 \\
\mathbf{1 3 . 8}\end{array}$ & $\begin{array}{r}151.8 \\
104.9 \\
\mathbf{9 3 . 1} \\
84.2 \\
\mathbf{8 8 . 5}\end{array}$ & $\begin{array}{l}58.3 \pm 6.8 \\
\mathbf{5 9 . 1} \pm \mathbf{3 . 4}\end{array}$ & 877.6 & 55.01 & 1001.4 & 54.69 & & \\
\hline 304 & $\begin{array}{l}\mathrm{H}_{2} \\
\mathrm{H}_{3} \\
\mathrm{H}_{11} \\
\mathbf{H}_{19}{ }^{a}\end{array}$ & $\begin{array}{l}21.2 \\
89.9 \\
26.8 \\
\mathbf{6 9 . 7}\end{array}$ & $\begin{array}{l}217.6 \\
282.4 \\
131.8 \\
\mathbf{2 9 5 . 3}\end{array}$ & $59.6 \pm 6.9$ & & & & & & \\
\hline 316 & $\begin{array}{l}\mathrm{H}_{2} \\
\mathbf{H}_{3}{ }^{a} \\
\mathrm{H}_{11} \\
\mathrm{H}_{19}\end{array}$ & $\begin{array}{r}17.8 \\
\mathbf{1 6 4 . 7} \\
20.1 \\
29.7\end{array}$ & $\begin{array}{l}259.2 \\
175.7 \\
295.3\end{array}$ & $60.9 \pm 7.1$ & 5229.2 & 55.05 & 5707.6 & 54.82 & 8642.4 & 53.73 \\
\hline 328 & $\begin{array}{l}\mathrm{H}_{2} \\
\mathrm{H}_{3} \\
\mathrm{H}_{11}\end{array}$ & $\begin{array}{l}16.8 \\
18.0 \\
12.8\end{array}$ & $\begin{array}{r}274.6 \\
196.2 \\
2779.5\end{array}$ & $62.1 \pm 7.2$ & & & & & & \\
\hline
\end{tabular}

${ }^{a}$ The coalescence temperature for this $\mathrm{H}$ atom, marked in bold. ${ }^{b}$ Values in the line for $\Delta v$ (column 3), $k_{\mathrm{e}}$ (column 4), and $\Delta G_{\mathrm{e}}$ (column 5), respectively, marked in bold italic.

$3^{\circ}$. Because $\mathrm{R}_{4}=\mathrm{CH}_{3} \mathrm{O}$ may also be involved in the formation of hydrogen bonds, product 7 is the most representative to elucidate the effect of intramolecular hydrogen bonds. By comparing parts $\mathrm{A}$ and $\mathrm{D}$ of Figure 5, it can be concluded that the electron densities of conformation $7 \mathbf{a}$ at the $6-31 \mathrm{G}^{*}$ and $6-311++\mathrm{G}^{* *}$ basis sets can almost be reproduced..$^{25}$ Therefore, the additional diffuse or polarization function has no obvious effect on the geometric properties or the energy differences, and the time-saving $6-31 \mathrm{G}^{*}$ basis set is efficient for subsequent studies.

4.4. Theoretical Calculations on the Solvent Effect. The thermodynamic cycle for the conformation interconversion in the gas phase and in solution was sketched in Scheme 2, where $\mathbf{t} 1$ represents the TS structure between conformation 1a and conformation $\mathbf{1 b}$ (see Figure 1E). The activation free energy in the gas phase was calculated to be 56.85 and $56.87 \mathrm{~kJ} \cdot \mathrm{mol}^{-1}$ at the B3LYP/6-31G* and the MP2/6-31G* theoretical levels, respectively. Costa et al. ${ }^{26}$ investigated the aquation process of cis-dichloro(ethylenediammine)platinum(II), concluding that the MP2 method was superior to the B3LYP method when dealing with the solvent effects. In consequence, these two theoretical methods were both evaluated and compared with each other.

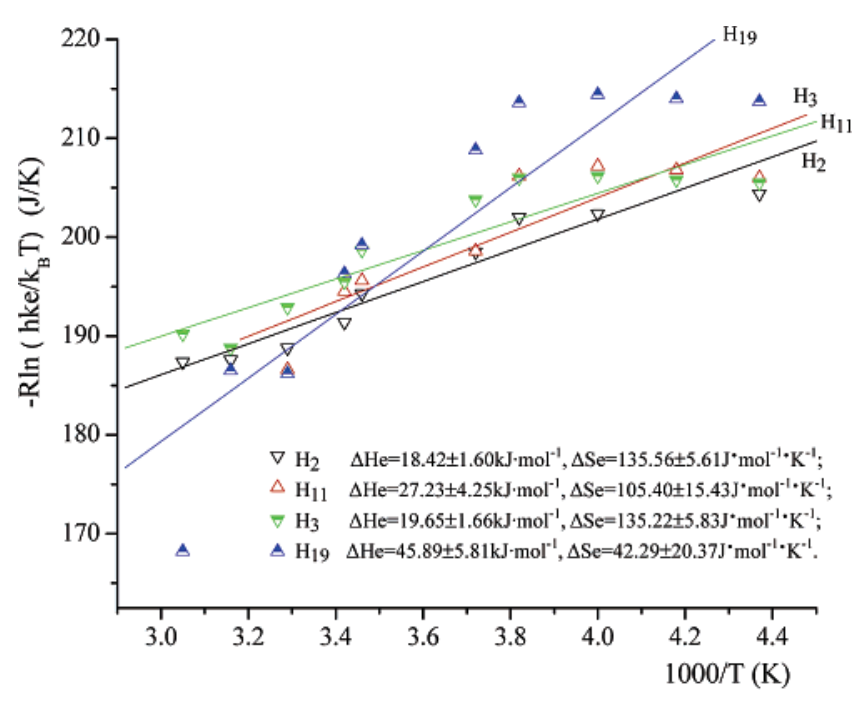

Figure 4. Thermodynamic enthalpies and entropies of the conformation interconversion between conformation $\mathbf{1 a}$ and conformation $\mathbf{1 b}$ for $\mathrm{H}_{2}$, $\mathrm{H}_{3}, \mathrm{H}_{11}$, and $\mathrm{H}_{19}$, respectively. 


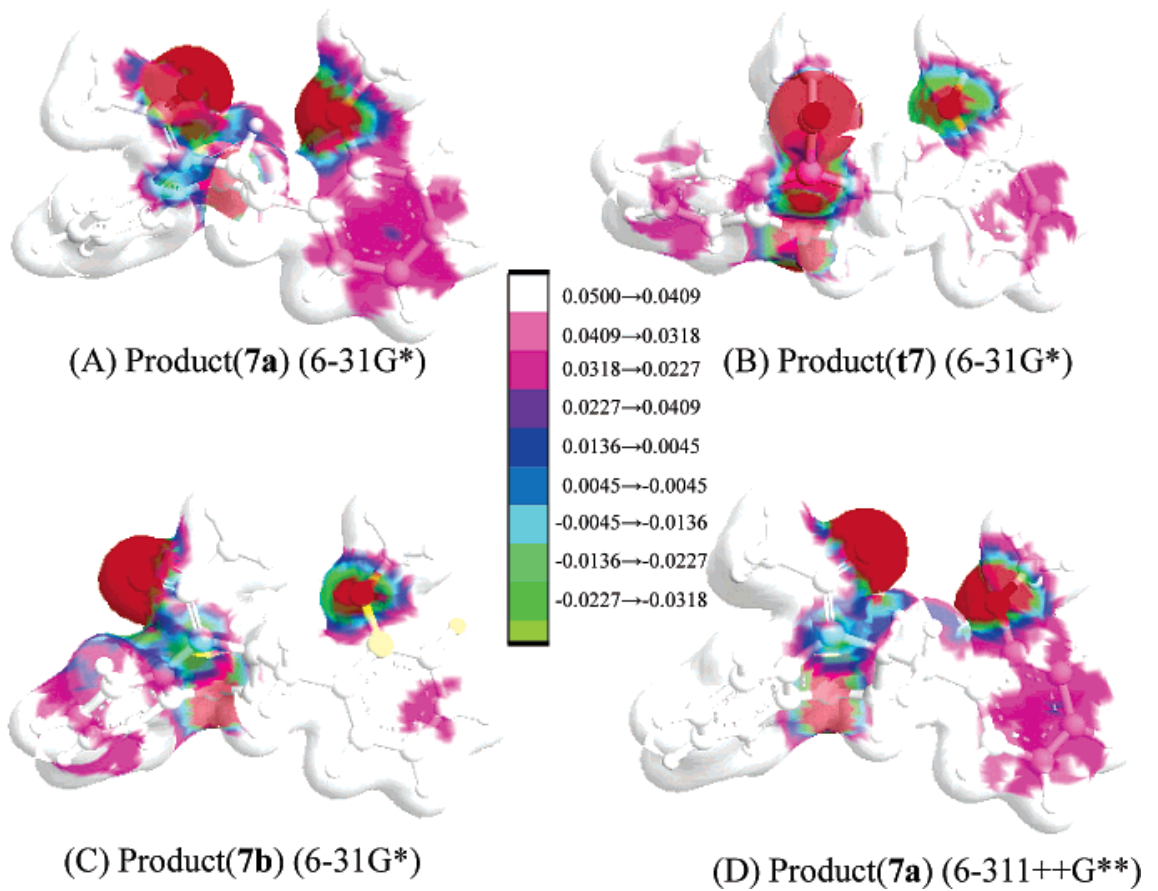

Figure 5. Electron densities for conformations 1a,b as well as their TS structure (t1).

SCHEME 2: Thermodynamic Cycle for the Interconversion between Conformation 1a and Conformation 1b in the Gas Phase and in Solution

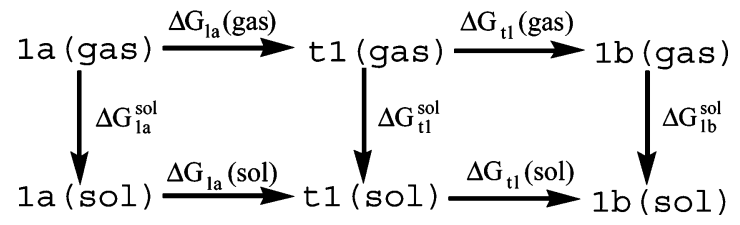

The solvent continuum effects were considered using the gasphase optimized geometries in conjunction with the PCM, where the van der Waals radii defined by Bondi were used for all the elements. ${ }^{27}$ The values are generally lower after the inclusion of solvent effects (see Table 1). In eq 1, the subscript $i$ in $\Delta G_{i}$, $\Delta S_{i}$, and $\Delta H_{i}$ is replaced by b (or $\mathrm{m}$ ) when treated by the B3LYP/6-31G* (or MP2/6-31G*) theoretical level with $\mathrm{CDCl}_{3}$ as the solvent and by $\mathrm{d}$ when treated by the MP2/6-31G* theoretical level with DMSO- $d_{6}$ as the solvent. At room temperature, the activation free energies in $\mathrm{CDCl}_{3}$ are 55.01 and $54.69 \mathrm{~kJ} \cdot \mathrm{mol}^{-1}$ at the B3LYP/6-31G* and MP2/6-31G* theoretical levels, respectively, in fine agreement with the experimental value of $58.3 \pm 6.8 \mathrm{~kJ} \cdot \mathrm{mol}^{-1} . \Delta G_{\mathrm{b}}$ is always slightly larger by the B3LYP/6-31G* than $\Delta G_{\mathrm{m}}$ by the MP2/ $6-31 G^{*}$ theoretical method, making the latter more consistent with the experimental value at lower temperatures, whereas the former is more consistent at higher temperatures. At each theoretical level, the changing tendency of the $\Delta G_{i}$ values is in fine accordance with the experimental findings even though the changing speed may differ greatly, which may be controlled by the current theoretical levels. MP2 seems to have no substantial advantage over B3LYP, probably a result of intramolecular hydrogen bonding involved in our system instead of intermolecular hydrogen bonding in the system of Costa et al. ${ }^{26}$

Supposing that DMSO- $d_{6}$ would not freeze at $229 \mathrm{~K}$, we calculated the activation free energies at 229,269 , and $316 \mathrm{~K}$. It is shown that, at each specified temperature, the activation free energy is smaller in DMSO- $d_{6}$ than in $\mathrm{CDCl}_{3}$. The interconversion rate in DMSO- $d_{6}$ is about 1.5 times faster than that in $\mathrm{CDCl}_{3}$ (see Table 1). Therefore, it is no surprise that although the variable-temperature NMR experiments were performed in DMSO- $d_{6}$ above the temperature of $296 \mathrm{~K}$, we still failed to observe the coalescence phenomena for $\mathrm{H}_{3}$ and $\mathrm{H}_{19}$ in DMSO- $d_{6}$ as in $\mathrm{CDCl}_{3}$.

4.5. Substitution Effect at the R1-R5 Positions. From the numerous products in Scheme 1, several representative products were picked out to investigate the substitution effect. Conformations of the same configuration as conformation 1a were named conformations $\mathbf{2 a}, \mathbf{3 a}, \mathbf{6 a}$, and $\mathbf{7 a}$, and those of the same configuration as conformation $\mathbf{1 b}$ were named conformations $\mathbf{2 b}, \mathbf{3 b}, \mathbf{6 b}$, and $\mathbf{7 b}$. Their TS structures were named $\mathbf{t} \mathbf{2}, \mathbf{t 3}, \mathbf{t 6}$, and $\mathbf{t} 7$, respectively.

All the TS structures were verified by frequency calculations, ensuring that only one imaginary frequency existed (see Figure 6 for the exact values). The $\mathrm{C}_{18}-\mathrm{N}$ bond of the TS structure is elongated by almost $0.060 \AA$ compared to those of the two conformations of each of the products, whereas the $\mathrm{C}=\mathrm{O}$ bonds were shortened by almost $0.015 \AA$. The $\mathrm{C}=\mathrm{O}$ bonds in the TS structures are approximately vertical to the $\mathrm{C}_{3} \mathrm{NC}_{10}$ plane, whereas they are nearly within the plane for all the stable conformations, which can be found from the $\mathrm{C}_{3} \mathrm{NC}_{18} \mathrm{O}$ dihedrals in Table 2. The electron density of the $\mathrm{O}$ from the acetyl group has some overlap with those of the $\mathrm{H}_{3}$ and $\mathrm{H}_{11}$ in conformation 7a and with $\mathrm{H}_{5}$ in conformation $\mathbf{7 b}$, as reflected by the orientations of the semipheres (see Figure 5A,C). However, the electron density formed a nearly perfect sphere in the TS structure, implying that no hydrogen bonds are formed with this $\mathrm{O}$.

As shown in Table 2 or Figure 6, the activation barrier decreases in the following order: product $\mathbf{6}(57.13)>\mathbf{3}(56.96)$ $>\mathbf{1}(56.85)>7(48.54)>2\left(40.93 \mathrm{~kJ} \cdot \mathrm{mol}^{-1}\right)$. The conformation interconversion is probably thermodynamically dominated because the activation barrier shows the same sequence as that of the reaction heats as follows: product $\mathbf{6}(18.85)>\mathbf{3}(17.27)$ $>\mathbf{1}(16.90)>\mathbf{2}(15.27)>\mathbf{7}\left(8.24 \mathrm{~kJ} \cdot \mathrm{mol}^{-1}\right)$, with product 7 being the only exception.

In product 3 , the replacing group, $\mathrm{R}_{2}=\mathrm{CH}_{3}$, is far from the acetyl group and there is almost no influence on the activation free energy as well as the reaction heat. Product $\mathbf{6}$ is an isomer 
TABLE 2: Geometric Parameters and Energy Differences $(\Delta E)$ for Conformations a and b as Well as Their TS Structures ${ }^{a}$

\begin{tabular}{|c|c|c|c|c|c|c|c|c|}
\hline & basis set & $\mathrm{C}_{18}-\mathrm{N}$ & $\mathrm{C}=\mathrm{O}$ & $\mathrm{O}-\mathrm{H}_{3}$ & $\mathrm{O}-\mathrm{H}_{11}$ & $\mathrm{O}-\mathrm{H}_{5}$ & $\Theta$ & $\Delta E$ \\
\hline \multirow[t]{2}{*}{$1 \mathbf{a}$} & $6-31 G^{*}$ & 1.392 & 1.227 & 2.349 & 2.481 & & -10.71 & $0^{b}$ \\
\hline & $6-311++\mathrm{G}^{* *}$ & 1.390 & 1.223 & 2.341 & 2.552 & & -11.19 & -599.57 \\
\hline \multirow[t]{2}{*}{$1 b$} & $6-31 G^{*}$ & 1.395 & 1.222 & & & 2.399 & -178.54 & 16.90 \\
\hline & $6-311++\mathrm{G}^{* *}$ & 1.393 & 1.218 & & & 2.464 & 178.60 & \\
\hline t1 & $6-31 G^{*}$ & 1.457 & 1.207 & 3.850 & 2.853 & 2.733 & -113.92 & 56.85 \\
\hline \multirow{2}{*}{$2 a$} & $6-31 G^{*}$ & 1.388 & 1.230 & 2.414 & 2.444 & & -14.38 & $0^{b}$ \\
\hline & $6-311++\mathrm{G}^{* *}$ & 1.386 & 1.224 & 2.408 & 2.509 & & -14.76 & -715.88 \\
\hline $2 \mathbf{b}$ & $6-31 \mathrm{G}^{*}$ & 1.394 & 1.225 & & & 2.194 & -159.55 & 15.73 \\
\hline t2 & $6-31 G^{*}$ & 1.449 & 1.214 & 3.851 & 2.782 & 2.761 & -106.22 & 40.93 \\
\hline \multirow[t]{2}{*}{$3 \mathbf{a}$} & $6-31 G^{*}$ & 1.392 & 1.227 & 2.351 & 2.479 & & -10.97 & $0^{b}$ \\
\hline & $6-311++\mathrm{G}^{* *}$ & 1.390 & 1.223 & 2.341 & 2.554 & & -11.42 & -624.09 \\
\hline $3 \mathbf{b}$ & $6-31 G^{*}$ & 1.395 & 1.222 & & & 2.397 & -178.69 & 17.27 \\
\hline t3 & $6-31 \mathrm{G}^{*}$ & 1.457 & 1.207 & 3.849 & 2.852 & 2.723 & -114.06 & 56.95 \\
\hline \multirow[t]{2}{*}{$6 a$} & $6-31 G^{*}$ & 1.391 & 1.227 & 2.367 & 2.484 & & -11.09 & $0^{b}$ \\
\hline & $6-311++\mathrm{G}^{* *}$ & 1.389 & 1.223 & 2.340 & 2.591 & & -11.09 & -624.99 \\
\hline $6 \mathbf{b}$ & $6-31 \mathrm{G}^{*}$ & 1.395 & 1.222 & & & 2.409 & -178.48 & 17.27 \\
\hline t6 & $6-31 G^{*}$ & 1.456 & 1.207 & 3.869 & 2.898 & 2.694 & -115.07 & 57.13 \\
\hline \multirow[t]{2}{*}{$7 \mathbf{a}$} & $6-31 G^{*}$ & 1.392 & 1.226 & 2.364 & 2.518 & & -11.19 & $0^{b}$ \\
\hline & $6-311++\mathrm{G}^{* *}$ & 1.390 & 1.221 & 2.359 & 2.582 & & -11.85 & -687.07 \\
\hline $7 b$ & $6-31 G^{*}$ & 1.395 & 1.222 & & & 2.382 & -176.95 & 8.24 \\
\hline $\mathbf{t} 7$ & $6-31 G^{*}$ & 1.458 & 1.207 & 3.808 & 2.737 & 2.826 & -109.67 & 48.54 \\
\hline $5 \mathbf{a}$ & $6-31 G^{*}$ & 1.395 & 1.226 & 2.351 & 2.476 & & -10.74 & \\
\hline 11 & $6-31 G^{*}$ & 1.393 & 1.225 & & & 2.421 & 177.13 & \\
\hline
\end{tabular}

${ }^{a}$ Units for distance in $\AA$, dihedral angle $(\Theta)$ in degrees, and energy difference in $\mathrm{kJ} \cdot \mathrm{mol}^{-1}$, respectively. ${ }^{b}$ Energy of conformation a was set to zero in each product.

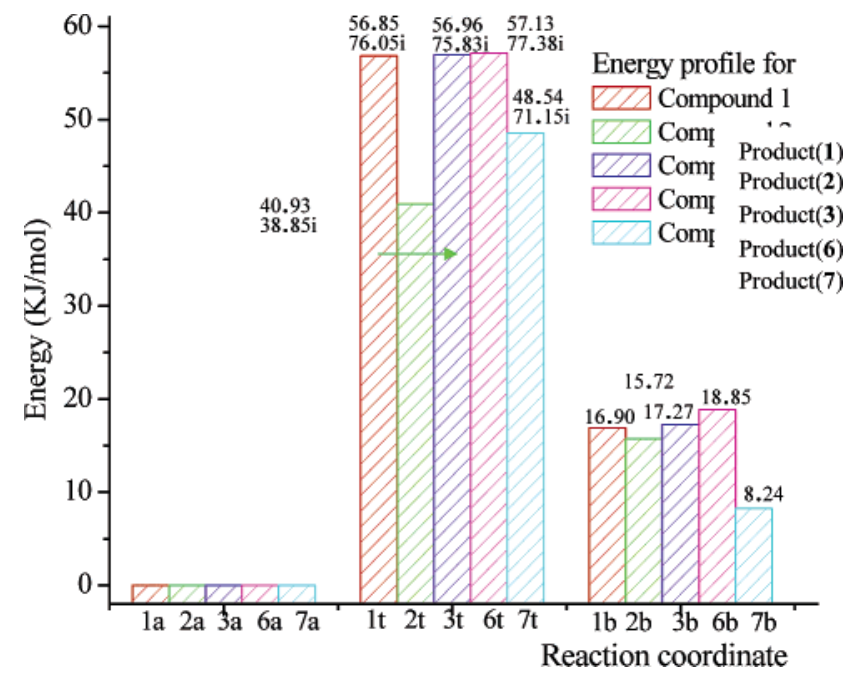

Figure 6. Potential energy profile vs the reaction coordinate for the interconversions between conformation a and conformation $b$. The energy of conformation a in each product was set to zero (energy units in $\mathrm{kJ} \cdot \mathrm{mol}^{-1}$ ), and the single imaginary frequencies of the TS structures were listed above the middle bars and terminated with the character "i".

of 3. As for conformation $\mathbf{6 a}$, the $\mathrm{O}$ from the acetyl group has some attraction toward the $\mathrm{H}$ from the $\mathrm{R}_{4}=\mathrm{CH}_{3}$ group, counteracting somewhat the mutual repulsion interaction. However, the two methyl groups in conformation $\mathbf{6 b}$ are located so close that a great repulsion will take place causing the energy difference between conformation $\mathbf{3 b}$ and conformation $\mathbf{6 b}$ (7.13 $\mathrm{kJ} \cdot \mathrm{mol}^{-1}$ ) to become larger than the energy difference between conformation $\mathbf{3 a}$ and conformation $\mathbf{6 a}\left(5.53 \mathrm{~kJ} \cdot \mathrm{mol}^{-1}\right)$.

What surprised us is that the substituted groups near the acetyl group in products $\mathbf{2}$ and $\mathbf{7}$ do not elevate the activation barrier but instead lower it somewhat, especially in the case of product 7. Two phenyl groups fall on the same side in conformation $\mathbf{2 a}$ and on either side in conformation $\mathbf{2} \mathbf{b}$, causing the latter to be more relaxed and stabilized. In conformation $\mathbf{7 a}$, hydrogen bonds with the $\mathrm{O}$ from the acetyl group were weakened by the competition with the $\mathrm{O}$ from $\mathrm{R}_{4}=\mathrm{CH}_{3} \mathrm{O}$ (see Table 2 for the lengths of hydrogen bonds compared with the corresponding values in conformation 1a). Moreover, the two $\mathrm{O}$ atoms repulse each other, as deduced from the two opposite semispheres of electron densities drawn in Figure 5A,D. On the contrary, in conformation $\mathbf{7 b}$, the surplus electron density of the $\mathrm{O}$ from the $\mathrm{R}_{4}=\mathrm{CH}_{3} \mathrm{O}$ group is well-dispersed. Therefore, the energy difference between conformation $\mathbf{7 a}$ and conformation $\mathbf{7 b}$ is lowered. This may lead to the contradiction between the sequence of activation barriers and the sequence of reaction heats.

\section{Conclusions}

Dynamic NMR experiments and ab initio density functional calculations were combined to study the conformation interconversion of novel chiral 3-alkyl-3,4- dihydro- $2 H$-benzo[1,4]oxazine derivatives. The main findings are summarized below:

1. From the variable-temperature $\mathrm{NMR}$ experiments in $\mathrm{CDCl}_{3}$ and DMSO- $d_{6}$, it can be found that ${ }^{1} \mathrm{H}$ and ${ }^{13} \mathrm{C}$ NMR spectral lines are severely broadened when the temperature is below about $375 \mathrm{~K}$. At $375 \mathrm{~K}$, the complete assignment of ${ }^{1} \mathrm{H}$ and ${ }^{13} \mathrm{C}$ NMR signals was achieved in DMSO- $d_{6}$, where the conformation interconversion is fast on the NMR time scale.

2. In $\mathrm{CDCl}_{3}$, the coalescence temperatures of $\mathrm{H}_{2}, \mathrm{H}_{3}, \mathrm{H}_{11}$, and $\mathrm{H}_{19}$ in product $\mathbf{1}$ are $289,304,292$, and $316 \mathrm{~K}$, with their corresponding $\Delta G_{\mathrm{e}}$ at $58.0 \pm 6.7,60.9 \pm 7.1,58.3 \pm 6.8$, and $59.6 \pm 6.9 \mathrm{~kJ} \cdot \mathrm{mol}^{-1}$, respectively; $\Delta G_{\mathrm{c}}$ for $\mathrm{H}_{2}$ and $\mathrm{H}_{11}$ equals 58.6 and $60.5 \mathrm{~kJ} \cdot \mathrm{mol}^{-1}$, respectively, agreeing well with the corresponding $\Delta G_{\mathrm{e}}$ values.

3 . The calculated results showed no obvious influence from the different basis sets, and the $6-31 \mathrm{G}^{*}$ basis set is qualified for treating similar systems with only intramolecular hydrogen bonding involved.

4. At each theoretical level, the changing tendencies of the calculated $\Delta G_{i}$ and $k_{i}$ are consistent with the experimental results. MP2 seems to have no substantial advantage over B3LYP, probably because only intramolecular hydrogen bonds are involved.

5. At each temperature, the interconversion rate in DMSO$d_{6}$ is calculated through the PCM to be approximately 1.5 times 
faster than the rate in $\mathrm{CDCl}_{3}$. Accordingly, the coalescence temperature for the same $\mathrm{H}$ is lower in DMSO- $d_{6}$ than in $\mathrm{CDCl}_{3}$, elucidating the failure in observing the coalescence phenomena in DMSO- $d_{6}$.

6. The substitution effect was studied by density functional calculations, with the interconversion barriers decreasing as follows: product $\mathbf{6}>\mathbf{3}>\mathbf{1}>\mathbf{7}>\mathbf{2}$. The interconversion processes may be thermodynamically controlled.

Acknowledgment. We gratefully acknowledge the financial support from the National Natural Science Foundation of China (No. 90210024). We thank Dr. B. Pietruszka for helpful discussions and Dr. X. L. Pan for reviewing the manuscript. Mr. W. Zhang is appreciated for the support he provided in computational resources.

Supporting Information Available: ${ }^{1} \mathrm{H}$ and ${ }^{13} \mathrm{C}$ NMR chemical shifts and coupling constants of the synthesized chiral products $\left(375 \mathrm{~K}\right.$ in DMSO- $\left.d_{6}\right),{ }^{1} \mathrm{H}$ and ${ }^{13} \mathrm{C}$ NMR spectra of product 1 in DMSO- $d_{6}$ at different temperatures, and ${ }^{1} \mathrm{H}$ NMR spectra of product 1 in $\mathrm{CDCl}_{3}$ at room temperature. This material is available free of charge via the Internet at http://pubs.acs.org.

\section{References and Notes}

(1) Bouzard, D. In Antibiotics and Antivial Compound; Krohn, K., Rirst, H. A., Maag, H., Eds.; VCH: Weinheim, 1993.

(2) Hooper, D. C.; Wolfson, J. S. Quinolone Antimicrobial Agents; American Society for Microbiology: Washington, DC, 1993.

(3) Shim, J. Y.; Collantes, E. R.; Welsh, W. J. J. Med. Chem. 1998 $41,4521$.

(4) McAllister, S. D.; Rizvi, G.; Anavi-Goffer, S.; Hurst, D. P.; BarnettNorris, J.; Lynch, D. L.; Reggio, P. H.; Abood, M. E. J. Med. Chem. 2003 46, 5139. 66,20

5) Kundu, N. G.; Chaudhuri, G.; Upadhyay, A. J. Org. Chem. 2001, 1679.

(7) Siener, T.; Holzgrabe, U.; Drosihn, S.; Brandt, W. J. Chem. Soc., Perkin Trans. 2 1999, 9, 1827.

(8) Katritzky, A. R.; Akhmedov, N. G.; Ghiviriga, I.; Steel, P. J. J. Chem. Soc., Perkin Trans. 2 2002, 11, 1816.
(9) Diaz-Quijada, G. A.; Weinberg, N.; Holdcroft, S.; Pinto, B. M. J. Phys. Chem. A 2002, 106, 1266.

(10) Grilli, S.; Lunazzi, L.; Mazzanti, A.; Pinamonti, M.; Anderson, J. E.; Ramana, C. V.; Koranne, P. S.; Gurjar, M. K. J. Org. Chem. 2002, 67, 6387.

(11) Brown, J.; Pawar, D. M.; Noe, E. A. J. Org. Chem. 2003, 68, 3420.

(12) Akhmedov, N. G.; Myshakin, E. M.; Hall, C. D. Magn. Reson. Chem. 2004, 42, 39.

(13) Jorge, G. O.; John, G.; Aloysius, S.; Robert, J. W. J. Am. Chem. Soc. 2004, 126, 6866 .

(14) Belletete, M.; Leclerc, M.; Durocher, G. J. Phys. Chem. 1994, 98 , 9450.

(15) Jose, C. C.; María, S. L.; Manuel, A. A. J. Am. Chem. Soc. 2004, 126,7311

(16) Frisch, M. J.; Trucks, G. W.; Schlegel, H. B.; Scuseria, G. E.; Robb, M. A.; Cheeseman, J. R.; Zakrzewski, V. G.; Montgomery, J. A., Jr.; Stratmann, R. E.; Burant, J. C.; Dapprich, S.; Millam, J. M.; Daniels, A. D.; Kudin, K. N.; Strain, M. C.; Farkas, O.; Tomasi, J.; Barone, V.; Cossi, M.; Cammi, R.; Mennucci, B.; Pomelli, C.; Adamo, C.; Clifford, S.; Ochterski, J.; Petersson, G. A.; Ayala, P. Y.; Cui, Q.; Morokuma, K.; Malick, D. K.; Rabuck, A. D.; Raghavachari, K.; Foresman, J. B.; Cioslowski, J.; Ortiz, J. V.; Stefanov, B. B.; Liu, G.; Liashenko, A.; Piskorz, P.; Komaromi, I.; Gomperts, R.; Martin, R. L.; Fox, D. J.; Keith, T.; Al-Laham, M. A Peng, C. Y.; Nanayakkara, A.; Gonzalez, C.; Challacombe, M.; Gill, P. M. W.; Johnson, B. G.; Chen, W.; Wong, M. W.; Andres, J. L.; Head-Gordon, M.; Replogle, E. S.; Pople, J. A. Gaussian 98, revision A.9; Gaussian, Inc.: Pittsburgh, PA, 1998.

(17) Becke, A. D. Phys. Rev. A: At., Mol., Opt. Phys. 1988, 38, 3098.

(18) Lee, C.; Yang, W.; Parr, R. G. Phys. Rev. B: Condens. Matter 1988, 37, 785

(19) Hehre, W. J.; Ditchfield, R.; Pople, J. A. J. Chem. Phys. 1972, 56, 2257.

(20) Cossi, M.; Barone, V.; Cammi, R.; Tomasi, J. Chem. Phys. Lett. 1996, 255,327

(21) Barone, V.; Cossi, M.; Tomasi, J. J. Chem. Phys. 1997, 107, 3210.

(22) Connors, K. A. Chemical kinetics - the study of reaction rate in solutions; Wiley: New York, 1990.

(23) Shen, Q. F. Carbon Nuclear Magnetic Resonance Spectra; Peking University Publisher: Peking, China, 1983.

(24) Pieeinni-Leopardi, C.; Fabre, O.; Reisse, J. Org. Magn. Reson. 1976, $8,233$.

(25) The electron densities were drawn with the aid of the software program Arguslab 3.0. It is available free via the Internet at http:// www.planaria-software.com.

(26) Costa, L. A. S.; Rocha, W. R.; De Almeida, W. B.; Dos Santos, H. F. Chem. Phys. Lett. 2004, 387, 182.

(27) Bondi, A. J. Chem. Phys. 1964, 68, 441. 